\title{
Intraventricular Air Embolus Causing Ischemic Stroke after Lung Biopsy
}

Tomás $\mathbf{J}^{*}$, Sargento-Freitas J, Paulino C, Gamboa F, and Camacho 0

Coimbra Universitary Hospital, Portugal

\section{Introduction}

Gas embolism is a rare potentially fatal pathology and a recognized cause of cerebral ischemia and stroke [1,2]. It is a dreaded complication following invasive medical procedures, such as transthoracic needle biopsy, traumatic lung injury and decompression accidents [3-7]. Arterial gas embolism is caused by the entry of gas into the pulmonary veins or directly into the arteries of the systemic circulation [8]. Another mechanism takes place when gas enters the arterial circulation through a right-to-left cardiac or intrapulmonary shunt or if passage of bubbles through the pulmonary capillary bed occurs. Injection of 2 $\mathrm{ml}$ of air into cerebral circulation can be fatal [9]. Cerebral lesion can result from intracranial artery occlusion, platelet clot development on the gas-blood interface, endothelial lesion or inflammatory activation. The purpose of this study is to report an uncommon cause of stroke following an invasive medical procedure and its management.

\section{Case Report}

A 64-year-old male, with a medical history of type II Diabetes Mellitus, dyslipidemia and arterial hypertension,was referred to the Pneumology Department to study a nodular pulmonary lesion detected on an ambulatory routine chest ray. The chest computed tomography (CT) scan showed a $2.5 \mathrm{~cm}$ nodule in the left lower lobe. A CT-guided transthoracic needle biopsy was performed and after this procedure, still in the CT table, the patient complained of sudden bilateral vision loss.

The control thoracic CT scan performed post-biopsy detected an air bubble at the apex of the left ventricle (Figure 1). Initial observation revealed total vision loss, the pupils were symmetric and equally reactive and the patient had a normal fundoscopic examination. There were no language defects, oculomotor impairment or weakness and no changes concerning osteotendinous and cutaneoplantar reflexes and axial and kinetic coordination. A cerebral CT scan performed immediately after the procedure showed no lesions. Subsequent brain magnetic resonance imaging (MRI) showed right parieto-occipital high

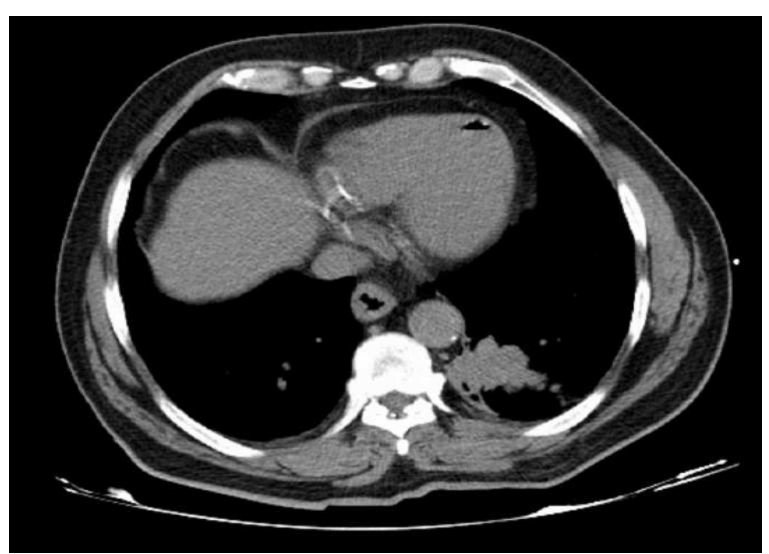

Figure 1: Control thoracic CT scan (axial view) obtained immediately after transthoracic needle biopsy shows abnormal presence of air in the left ventricle.

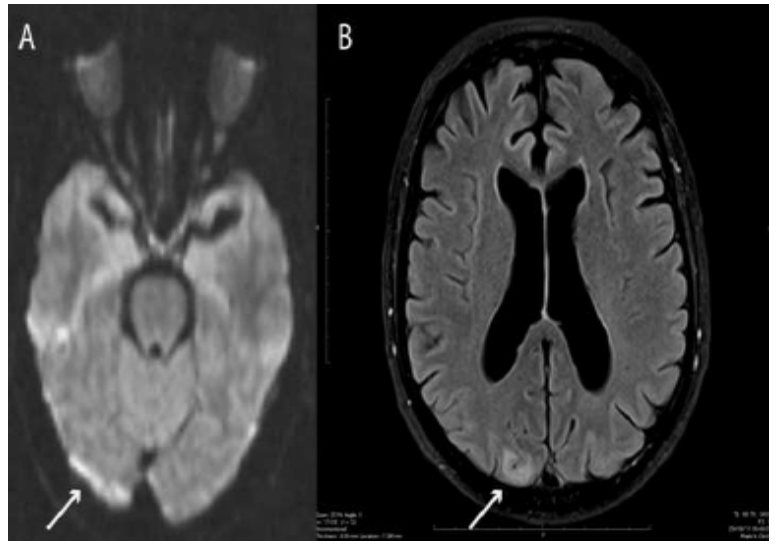

Figure 2: MRI performed after first neurological symptoms. (A) Axial diffusion-weighted MRI demonstrates right parieto-occipital increased diffusion restriction (arrow). (B) Axial FLAIR-weighted MRI shows high signal intensity in the same region (arrow).

signal intensity in FLAIR-weighted images with restriction in diffusion imaging (Figure 2).

Within three hours after the biopsy the patient developed right hemiparesis (grade 4/5). A transcranial and cervical ultrasound examination excluded right-left shunt (after agitated saline solution administration) and revealed right posterior cerebral artery occlusion (P1 segment), which was recanalized as demonstrated by subsequent cerebral angio-CT scan.

Twelve hours after the first neurological symptoms, the patient started hyperbaric oxygen therapy, consist in a total of five sessions (once daily): one at 2.8 atmospheres for 5 hours, followed by four remaining 2 hour sessions at 2.5 atmospheres. Forty eight hours after the initiation of treatment the patient had no motor deficits, although the visual impairment remained. At the fifth day the patient recovered his vision and there were no focal signs on neurological examination. As a complication of hyperbaric oxygen therapy, the patient developed bilateral hemotympanum.

\section{Discussion}

This case provides visual evidence for one of the presumed mechanisms of ischemic brain lesion after CT-guid transthoracic

*Corresponding author: José Tomás, Coimbra Universitary Hospital, Portugal, Tel: 35121820585; E-mail: jmst85@gmail.com

Received May 21, 2015; Accepted June 02, 2015; Published June 04, 2015

Citation: Tomás J, Sargento-Freitas J, Paulino C, Gamboa F, Camacho O (2015) Intraventricular Air Embolus Causing Ischemic Stroke after Lung Biopsy. J Neurol Disord 3: 238. doi: 10.4172/2329-6895.1000238

Copyright: ( $\odot 2015$ Tomás J, et al. This is an open-access article distributed under the terms of the Creative Commons Attribution License, which permits unrestricted use, distribution, and reproduction in any medium, provided the original author and source are credited. 
needle biopsy: migration of air emboli through pulmonary veins, left cardiac chambers and finally the systemic circulation. Air embolism is a rare complication of pulmonary invasive procedures, with only six cases described in a large series of 9783 biopsies (0.061\%) [10]. More recently, Ishii et al., reported air embolism as a complication of CTguided lung biopsy in $0.45 \%$ ( 10 of 2,216$)$ patients from five institutions [11]. It is presumed to occur by two mechanisms. First, if the tip of the biopsy needle is lodged in a pulmonary vein and the inner stylet is removed, air embolism can occur during rapid inspiration when the atmospheric pressure exceeds the pulmonary venous pressure. Second, when a needle simultaneously traverses an air-containing space (airway for example) and adjacent pulmonary vein, a fistula can occur and air will enter the vein when the alveolar air pressure is greater than the pulmonary venous pressure - for example while coughing [12]. From pulmonary veins the gas could travel to the left heart. This case confirms this theory, with the visualization of an air bubble inside the left ventricle in the control thoracic CT scan. Systemic embolization of gas from the left ventricle into the cerebral circulation justified the neurological symptoms. Bilateral visual loss with preserved papillar reflexes (cortical blindness) suggesting a bilateral brain posterior circulation occlusion and subsequent right hemiparesis that is not typical of posterior circulation infarcts could mean that the patient probably underwent at least two cerebral embolisms. The diagnosis was made by the temporal correlation between the procedure, the onset of neurological symptoms and the compatible radiological findings. Hyperbaric oxygen therapy reduces the volume of the embolus (effect of the high barometric pressure), enables gas removal by denitrogenation (effect of the hyperoxygenation), maintains oxygenation in the ischemic tissues and decreases intracranial pressure and cerebral edema formation [13]. It has been used to manage cerebral dysfunction due to air embolism with good results and its beneficial effect is greatest when administered early [14]. Nevertheless, the patient described was treated twelve hours after the diagnosis, with no stroke recurrence and recovering all neurological deficits at the end of the fifth session.

\section{Conclusion}

In invasive procedures such as needle lung biopsy, arterial gas embolism can be a cause of cerebral ischemia and despit its rarity, it remains important to be recognized, as it requires emergent hyperbaric oxygen therapy.

\section{Competing Interests}

The authors declare no financial or non-financial competing interests. Related papers had not been already published or under consideration for publication. No undisclosed groups or persons have had a primary role in the manuscript preparation. All authors have seen and approved the submitted version of the article and accept responsibility for its content.

\section{Authors' Contributions}

JT have made substantial contributions to conception and design of the manuscript. All authors have made contributions to acquisition and analysis of data, read and approved the final manuscript.

\section{Acknowledgements}

The authors thank Carmo Macário and César Nunes for substantial role in the management of this case.

\section{References}

1. Bessereau J, Genotelle N, Chabbaut C, Huon A, Tabah A, et al. (2010) Longterm outcome of iatrogenic gas embolism. Intensive Care Med 36: 1180-1187.

2. Rivara CB, Chevrolet JC, Gasche Y, Charbonney E (2008) Fatal brain gas embolism during non-invasive positive pressure ventilation. BMJ Case Rep.

3. Thomas R, Thangakunam B, Cherian RA, Gupta R, Christopher DJ (2011) Cerebral air embolism complicating CT-guided trans-thoracic needle biopsy of the lung. Clin Respir J 5: e1-3.

4. Lederer W, Schlimp CJ, Glodny B, Wiedermann FJ (2011) Air embolism during CT-guided transthoracic needle biopsy. BMJ Case Rep.

5. Perinel Ragey S, Garnier P, Vergnon JM (2013) Complete resolution of cerebra air embolism secondary to a transbronchial needle aspiration. Respiration 86: 504-517.

6. Shin KM, Lim JK, Kim CH (2014) Delayed presentation of cerebellar and spinal cord infarction as a complication of computed tomography-guided transthoracic lung biopsy: a case report. Journal of medical case reports 8: 272.

7. Suzuki K, Ueda M, Muraga K, Abe A, Suda S, et al. (2013) An unusual cerebra air embolism developing within the posterior circulation territory after a needle lung biopsy. Internal medicine 52: 115-117.

8. Menendez-Gonzalez M, Oliva-Nacarino P, Alvarez-Cofino A (2007) Cerebral gas embolism caused by pleural fibrinolytic treatment. Stroke 38:2602-2604.

9. Ho AM (1999) Is emergency thoracotomy always the most appropriate immediate intervention for systemic air embolism after lung trauma? Chest 116: 234-237.

10. Tomiyama N, Yasuhara Y, Nakajima Y, Adachi S, Arai Y, et al. (2006) CT-guided needle biopsy of lung lesions: a survey of severe complication based on 9783 biopsies in Japan. European journal of radiology 59: 60-64.

11. Ishii H, Hiraki T, Gobara H, Fujiwara H, Mimura H, et al. (2014) Risk factors for systemic air embolism as a complication of percutaneous CT-guided lung biopsy: multicenter case-control study. Cardiovascular and interventional radiology 37:1312-1320.

12. Wu CC, Maher MM, Shepard JA (2011) Complications of CT-guided percutaneous needle biopsy of the chest: prevention and management. AJR American journal of roentgenology 196: W678-682.

13. Mathieu D, Poisot D, Wattel F (1986) Oxygénothérapie hyperbare en réanimation. Réanimation, soins intensifs, médecine d'urgence 2: 13.

14. Tekle WG, Adkinson CD, Chaudhry SA, Jadhav V, Hassan AE, et al. (2013) Factors associated with favorable response to hyperbaric oxygen therapy among patients presenting with iatrogenic cerebral arterial gas embolism. Neurocritical care 18: 228-33. 